\title{
Cross-scale Perspectives: Integrating Long-term and High-frequency Data into Our Understanding of Communities and Ecosystems
}

An organized oral session at the 100th annual ESA meeting on Friday, 14 August 2015, organized by Cayelan C. Carey and Kathryn L. Cottingham

Cayelan C. Carey ${ }^{1}$ and Kathryn L. Cottingham ${ }^{2}$

${ }^{1}$ Department of Biological Sciences, Virginia Tech, 1405 Perry Street, Blacksburg, Virginia 24061 USA

${ }^{2}$ Department of Biological Sciences, Dartmouth College, Class of 1978 Life Sciences Center,

78 College Street, Hanover, New Hampshire 03755 USA

Ecologists are amassing extensive data sets that include both long-term records documenting trends and variability in natural systems on inter-annual to decadal time scales and sensor-based measurements on minute to subhourly scales for extended periods (Hampton et al. 2013). Together, these long-term and high-frequency data are contributing to our ecological understanding. Although there have been several previous ESA sessions that have explored the insights provided by either long-term data or highfrequency data, to our knowledge this organized oral session provided one of the first opportunities to synthesize the lessons learned from leveraging both long-term data and high-frequency approaches.

The session included speakers at a variety of career stages and institutions chosen specifically for their unique and complementary perspectives on high-frequency and long-term data collection from desert ecosystems, grasslands, forests, streams, lakes, and coral reefs. While the focus of the session was on the ecological insights gained by using high-frequency and/or long-term data, the speakers also discussed the data approaches used to collect, manage, and analyze time series, as well as the inherent challenges in harnessing "big data" for ecology.

Scott Collins (University of New Mexico) kicked off the session by describing the use of sensor arrays to study responses to precipitation experiments in the United States and China (EDGE, edge. biology.colostate.edu). Collins emphasized the fallibility of sensors during long-term deployments, and how this unreliability resulted in data gaps that necessitated aggregating data to coarser temporal intervals than planned. Collins advised ecologists collecting sensor data to develop plans for dealing with data gaps a priori and to think carefully about what these data are telling us: e.g., soil $\mathrm{CO}_{2}$ sensors give measurements of $\mathrm{CO}_{2}$ concentrations, which then need to be interpreted carefully to get to the variables that we are actually interested in, e.g., soil respiration.

Kim La Pierre (University of California, Berkeley) presented findings from a long-term ecological research (LTER) synthesis of plant community responses to factorial experiments manipulating multiple components of global change (e.g., nutrient concentrations, water availability; corredata.weebly.com). Unlike aggregate ecosystem parameters, whose responses were not affected by the duration or number of global change factors simultaneously manipulated (Leuzinger et al. 2011), community properties were much more sensitive and effects strengthened with time and number of global change treatments. Thus, a key take-home message was that long-term experiments are important to understanding the magnitude and interactions of global change effects, especially of ongoing "press" perturbations. As such, La Pierre recommended that ecologists conduct studies that manipulate multiple drivers simultaneously over periods longer than 3 years. 
Jack Webster (Virginia Tech) used $>40$ years of stream nitrogen $(\mathrm{N})$ monitoring data from watersheds at the Coweeta Hydrologic Lab and LTER site in North Carolina to demonstrate how responses to deforestation in the southeastern United States are very different from the textbook paradigm derived from studies at the Hubbard Brook Experimental Forest in New Hampshire (Bormann and Likens 1994). At Coweeta, deforestation led to a regime shift in $\mathrm{N}$ dynamics, with a shift from biological control of $\mathrm{N}$ export to hydrological control due to a change in the dominant tree species during recovery from logging (Webster et al. 2014). Webster predicted that it will take at least two centuries for stream $\mathrm{N}$ cycling to return to baseline prelogging levels.

Tanner Williamson (Miami University of Ohio) compared the time scales and relative importance of external vs. internal loading of $\mathrm{N}$ and phosphorus (P) to the Acton Lake watershed (Ohio, USA) using both high-frequency and long-term data. External loading from the agricultural watershed exhibited seasonal spikes, with most loading occurring in spring months, whereas internal loading by gizzard shad fish dominated the growing season (April-October) nutrient budget. He predicted that algal biomass during the peak growing season responds more strongly to the internal, fish-derived nutrient subsidy because it is both larger and more predictable than external loads.

Paul Hanson (University of Wisconsin-Madison) presented a model that connected daily lake carbon (C) metabolism and its consequences for long-term organic $\mathrm{C}$ cycling. Hanson identified the temporal scale of data collection and modeling as a major challenge for resolving lake $\mathrm{C}$ budgets: daily, seasonal, and decadal $\mathrm{C}$ budgets give varying answers as to if lakes are $\mathrm{C}$ sinks or sources in the landscape. Similar to Collins, Hanson pointed out that the oxygen sensors deployed in lakes give us gas flux measurements but not organic $\mathrm{C}$ pools - and thus, interpreting sensor data was again noted as a challenge. Hanson also echoed La Pierre's call for long-term experiments, advocating for lake experiments manipulating C loading to better understand the controls of short-term and long-term ecosystem responses.

Steve Carpenter (University of Wisconsin-Madison) reported on a whole-ecosystem experiment to test whether it is possible to detect warnings of an impending regime shift in time to take preventive action, using statistical tests applied to minute-scale sensor data. To the surprise of many in the audience, he and his collaborators successfully interpreted signals from sensors of oxygen, phycocyanin, and chlorophyll, and turned off daily nutrient additions to a lake before a large cyanobacterial bloom developed. His take-home message was that high-frequency data can have a role in ecosystem management, though different ecosystems may exhibit varying responses to the same stressor.

Kathy Cottingham (Dartmouth) described a 10-year study to understand the development of cyanobacterial blooms in a low-nutrient lake in New Hampshire, USA using a combination of daily samples of cyanobacteria collected by a citizen scientist, weekly samples by researchers, and minute-scale sensor data for temperature and light (Carey et al. 2014). Cottingham challenged the ecological community to develop better ways to integrate high-frequency abiotic data with low-frequency biotic measurements without resorting to summary statistics.

Paralleling Williamson's talk, Alexandra Gerling (Virginia Tech) evaluated the importance of external nutrient loading vs. within-lake nutrient recycling - this time by chemical mechanisms rather than biological - for N and P budgets in Falling Creek Reservoir, Virginia (USA). Taking advantage of minute-resolution oxygen sensors, an experimental hypolimnetic oxygenation system, and the ability to 
manipulate external loading from the upstream reservoir, Gerling showed that the reservoir was a net sink of $\mathrm{N}$ and $\mathrm{P}$ and thus provides an important ecosystem service in reducing nutrient loads to downstream ecosystems (Gerling et al. 2016).

Returning to land and moving north to the boreal forest, Jennie McLaren (University of Texas at El Paso) evaluated the long-term (20-year) effects of nutrient fertilization (control vs. NPK) and herbivory (open vs. snowshoe hare exclosures) on plant communities and nutrient cycling, as well as the potential for recovery from these treatments. McLaren joked that her study predated affordable sensors and thus used an army of undergraduates instead. Surprisingly, snowshoe hare exclosures had little effect on the forest understory community or on soils, though fertilization did shift the composition of the plant community. In a parallel experiment examining the effects of long-term fertilization, McLaren found that recovery of the plant and microbial communities from fertilization is still ongoing.

Finally, Stuart Sandin (Scripps Institution of Oceanography, University of California-San Diego) described strategies to track changes in coral reefs across both time and space in the central Pacific, using a combination of large-scale mapping using digital photography and photomosaics, remote-sensed satellite data (e.g., sea surface temperatures [SST], chlorophyll), and in-ocean buoys (e.g., wave energy). A key focus of his team's work is whether human exploitation drives communities toward earlier successional structures. Sandin found that generalized additive models predict coral community structure from SST, chlorophyll, and waves near uninhabited islands but not uninhabited models, suggesting that humans alter biophysical coupling (Williams et al. 2015).

Collectively, the speakers made it clear that both long-term and high-frequency data streams are important to ecology, but that there are some common challenges that transcend ecosystem type and research question. We identified four integrative themes across the talks. First, long-term observational studies are extremely important for establishing context and baseline environmental conditions. Many of the speakers harnessed data collected as part of a LTER site or a LTER environmental in biology study: collectively, the 10 talks reported on more than 150 years of monitoring data (!). Second, experiments provide a powerful approach for testing hypotheses, especially if done at large spatial scales or over many years: short-term responses were not always indicative of long-term dynamics. Third, as ecology becomes increasingly "sensored," we need to be aware of sensor shortcomings: they often fail, collect erroneous data, and may not truly capture the response variables of interest. Ecologists need to be aware of these issues before they deploy expensive sensor arrays and have a plan in place for dealing with sensor gaps, because they will happen. Fourth, downscaling high-frequency data to lower temporal resolution is challenging. Several speakers wrestled with how to decide on the appropriate temporal resolution for data analysis, especially when analyses of the same variable at different temporal scales yield different answers.

We organized this session to see how ecologists across subfields wrestle with the challenge of integrating decades of long-term data, usually collected at coarse time scales (e.g., weeks to months to years), with fewer years of high-frequency data collected at second to minute to hour time scales. No clear recommendations or best practices emerged from these talks, but it is clear that cross-ecosystem communication will be essential to developing effective strategies for effectively working across temporal scales. With new sensor networks coming online every year, our goal is to spur synthesis working groups collaborating across ecosystems to drive this field forward. 


\section{Literature cited}

Bormann, F. H., and G. Likens. 1994. Pattern and process in a forested ecosystem. Pages 272. Springer-Verlag, New York, New York, USA.

Carey, C. C., K. C. Weathers, H. A. Ewing, M. L. Greer and K. L. Cottingham. 2014. Spatial and temporal variability in recruitment of the cyanobacterium Gloeotrichia echinulata in an oligotrophic lake. Freshwater Science. 33:577-592.

Gerling, A. B., Z. W. Munger, J. P. Doubek, K. D. Hamre, P. A. Gantzer, J. C. Little and C. C. Carey. 2016. Whole-catchment manipulations of internal and external loading reveal the sensitivity of a century-old reservoir to hypoxia. Ecosystems. DOI: 10.1007/s10021-015-9951-0.

Hampton, S. E., C. Strasser, A. Batcheller, W. Gram, C. Duke, J. Tewksbury and J. Porter. 2013. Big data and the future of ecology. Frontiers in Ecology and the Environment 11:156-162.

Leuzinger, S., Y. Luo, C. Beier, W. Dieleman, S. Vicca and C. Korner. 2011. Do global change experiments overestimate impacts on terrestrial ecosystems? Trends in Ecology \& Evolution. 26:236-241.

Webster, J. R., W. T. Swank, J. M. Vose, J. E. Knoepp and K. J. Elliott. 2014. Ecosystem stability and forest watershed management: a synthesis of 30+ years of research on WS 7. Pages 229-247 in W. T. Swank and J. R. Webster, editors. Long-term response of a forest watershed ecosystem: clearcutting in the southern Appalachians. Oxford University Press, New York, New York, USA.

Williams, G. J., J. J. M. Gove, Y. Eynau, B. J. Zgliczynski and S. A. Sandin. 2015. Local human impacts decouple natural biophysical relationships on Pacific coral reefs. Ecography 38:751-761.

132 Bulletin of the Ecological Society of America, 97(1) 